\title{
NLP Methods Of Motivation: Metaprograms and Reframing
}

\author{
Bogdan - Alexandru, FURDUESCU \\ Valahia University of Targoviste, \\ 35 Lt. Stancu lon Street, Building D, \\ bogdan_af@yahoo.com
}

\begin{abstract}
People are the most important asset category that an organization can use; none of them can exist without the human resources that make it up. However, paradoxically, they are also the only asset that can act against the goals of the organisation. From the same perspective, now, people can choose where to work or leave if they feel no pleasure anymore. Those who want to improve their living standards and reach a balance in their professional life will decide to leave their job if it is no longer satisfactory. a very important issue in the day-to-day activity of man is the motivation he/she feels for what he/she is doing. Motivation is a general term that describes the process of initiation, orientation and maintenance of physical and psychological activities, is a broad concept that includes a series of internal mechanisms, such as: the preference given to one activity over other activities, the enthusiasm and the force of a person's reactions, the persistence of some organized action patterns (models) to achieve relevant objectives.
\end{abstract}

Keywords: metaprograms, motivation, methods, NLP, reframing.

JELClassification: 015.

\section{Introduction}

Motivation is a a complex notion whose content cannot be rigorously dissected and highlighted because the reasons for employees' action cannot be directly observed and measured but deduced from their behavior. a continuous assessment of an organization's performance, studping its financial position, monitoring and counteracting risk factors, appreciation of the prospects of increasing its value, listing on the stock exchange, promoting efficient investments, maintaining balanced contractual relations with investors are permanent challenges for the managers of organizations who are trying to maintain themselves on a more internationally competitive market.

\section{NLP methods of motivation}

In terms of management and leadership, the main methods refer to "the encapsulation of an action trigger in certain contexts, so that they are not easily 
HOLISTICA Vol 10, Issue 1, 2019

identifiable" [losif, C.M., 2013, p. 69]. "Encapsulation of a message has the property of making it invisible, but at the same time it keeps its properties" [Iosif C. M., Socaciu, T., 2009, p. 130].among the most used action triggers there are [losif, C.M., 2013, pp. 69-70]: redirecting attention (is relatively easy to achieve, given that our mental structure usually goes the same way), the exploitation of the limited concentration capability (the more someone talks, the more they can split their time into small pieces, and the trigger can be hidden between several words), waiting time (another opportunity that can be used to convey an encapsulated command) and fragmentation of sentences (in order to transmit a message more easily, a certain linguistic structure must be deformed, broken, so that the brain takes a certain amount of time to accommodate and the message passes more easily through the different barriers of the consciousness); these trigger factors are useful within organisations, helping us to realize when an individual does not tell the truth, invents events, is fearful or fails to adapt within the organization. How NLP methods are used is presented in Figure no.1:

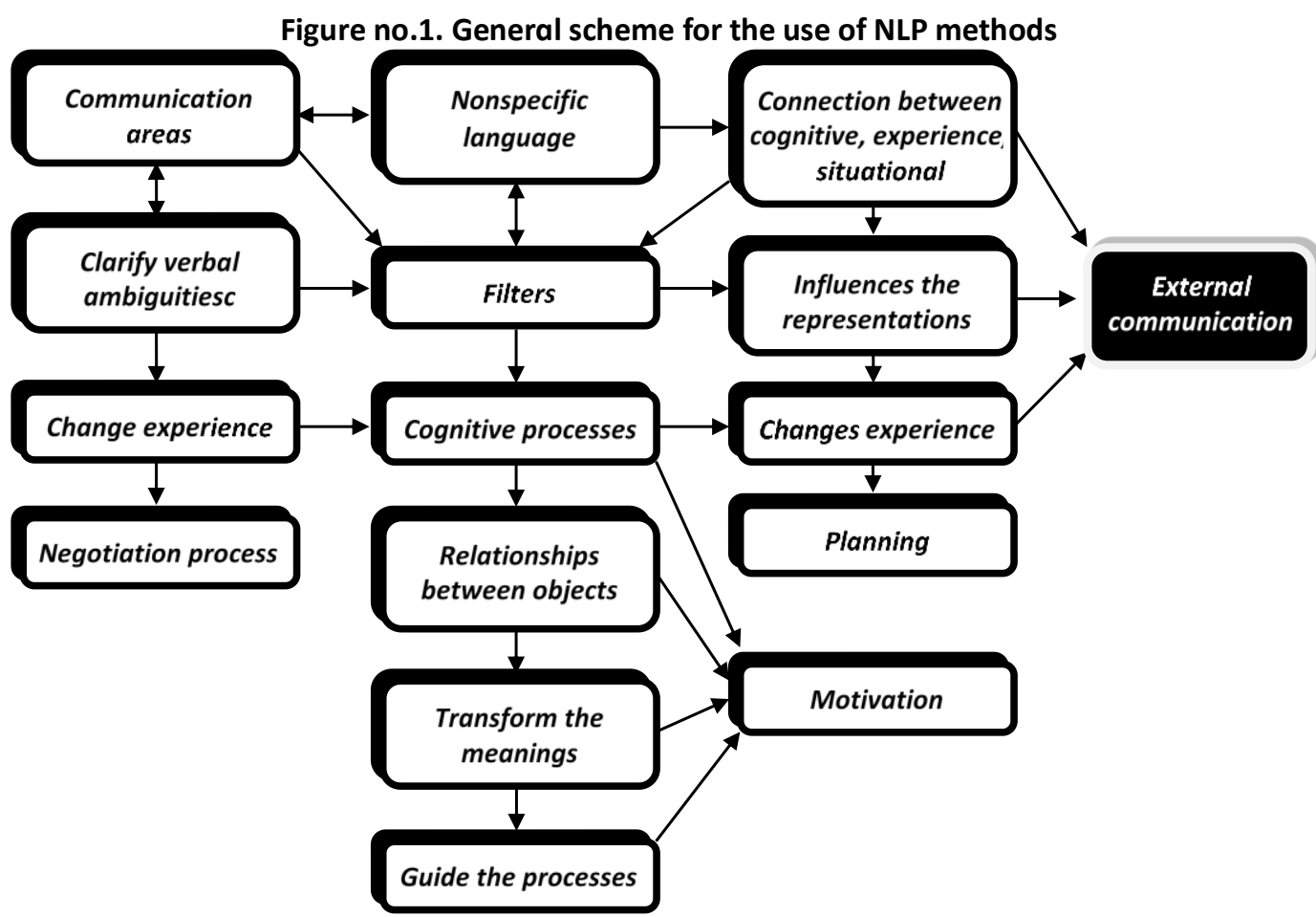

Source: own adaptation after losif, C.M., 2013, p. 68. 


\section{Metaprograms}

In the book "Bazele programarii neurolingvistice" ("The basics of NLP"), published in 2014, Dilts, R.B., defines metaprograms as follows [Dilts, R.B., 2014, p. 264]:

- $\quad$ a level of mental programming that determines how we classify, orient and divide experiences. Our meta programs are more abstract than our specific thinking strategies; they define our general approach to a particular aspect rather than to the details of our thinking process."

- $\quad$ "The mental/perceptual programs for sorting and paying attention to stimuli, perceptual filters that govern attention, sometimes "neuro-sorts," or meta-processes."

As Bandler, R.W., saps, metaprograms are programs by which decisions are made which influence consciousness on the basis of the information received from the subconscious and which it submits to a particular filtering process. "Meta programs represent the processes by which a person sorts his/her experiences, but also reacts to different stimuli in the environment." [Bandler, R.W., La Valle, J., 1996, p. 106].

"The role of meta programs is to filter the information coming up dailv from the environment and assailing the person. They 'sort' the information received according to the stimuli, keeping the most important ones and sending them to the brain to be processed, after having passed the filter barriers of the meta programs" [losif, C.M., 2013, p. 58]. There are two patterns of meta programs, respectively motivational patterns (used to maintain the motivation of a person at a high level) and working patterns (help to establish a relationship between a person's metal processes and the different processes in the organization). Once created, patterns allow an individual to get the same results, regardless of the situation. also, they allow him/her to see both his/her own actions and those around him/her. Each individual has his/her metaprograms set in a special way, the patterns being influenced by the three phases of the Disney model: The Dreamer, The Realist and The Critic. NLP is based on the idea of the unbounded and unexplored character of the human being:"What lies behind us and what lies ahead of us are tiny matters compared to what lies within us" [Haskins,H.S., 1947, p.BR2]. Inspiration and despair are the impetus that motivates the individual to success. They are "procedures" and "strategies" that set, select, or configure the "environment" for other "procedures" and "strategies" just like an operating spstem does for the computer. 
Metaprograms are structured on three levels [Dilts, R.B., 2007, p. 48]: logical (which includes identity, beliefs and abilities), behavior and environmentand self (which includes references to one's own being and to others).When a person manages to combine all three axes it means, on the one hand, that he/she successfully meets the demands of the workplace and, on the other hand, he/she copes with all external pressures, all sources of stress, and can act positively not only for him/her but also for the organization.

In order to pass certain information to the brain, where it will be processed, meta programs use: (1) the association-dissociation filter (the association filter allows us to experience feelings at maximum intensity, regardless of context; moving away from unpleasant situations is done with the help of the dissociation filters) [Knight, S., 2004, p. 154], (2) the filter that is close to - far from the goal.(the filter that is close to the goal represents the ability of a person to focus on achieving a particular goal; a person's ability not to think about a particular goal is called thinking away from purpose)[Knight, S., 2004, p. 157], (3) matching - mismatching filter (matching filter helps a person in a certain situation find all common elements or similarities in a particular situation, while mismatching filter helps a person to notice all the elements that do not fit in a certain situation that are devoid of a certain logic) [losif, C.M., 2013, p. 60], (4) large-scale filter and small-scale filter (large-scale filter helps a person make a description, referring to the big elements in that space (window, surface, door, etc.); small-scale filter, in the same description, it helps to report to small elements in that space (flower, fruit, mug, picture, etc.) [losif, C.M., 2013, p. 60], (5) the past-present-future filter (these filters show the relationship that some people have with time, how they project their existence, to what period of their life) [losif, C.M., 2013, p. 60], (6) the activity - person - object place - time filter (by combining five distinct filters, a compound filter is obtained; a certain action must be identified by a principal element -activity, person, object, place, time - so that it will also give the main filter that will act on that event) and (7) internal - external filter (the use of the external filter leads to finding stronger sources of motivation than those generated by the internal filter, which is reflected in the achievement of the fixed objectives) [Knight, S., 2004, p. 162].

There are two styles of motivation: closeness to what is desired and farness from what is not desired. They constitute what NLP calls motivational orientation [Vagu, P., Stegaroiu, I., 2007, p. 410], a mental program that affects our whole life [andreas, S., Faulkner, C., 2008, p. 59-60]. The individual, irrespective of his/her social status, has developed - at the biological level - both motivations, "towards" (pleasure, comfort, relaxation) and "away from" (pain, discomfort, stress), these being different ways of motivation and being useful in 
various situations. Moreover, the individual uses the same mental program in different situations. The effects of motivation direction show medium and extreme advantages and disadvantages: on the one hand, some individuals are very motivated "towards", on the other hand motivated individuals, who are "away from", are too scared to act in any way; trying to solve the problem, they may forget the motivation of their action [Vagu, P., Stegaroiu, I., 2007, p. 410].

Metaprograms are used as a motivation tool, suggesting a detailed hierarchy of what can motivate the individual when committing to an action. Meta programs design a "macro-strategy", a"macro-program", in NLP, the word "meta" meaning "about".Thus, meta programs are programs about programs,are strategieswhich include other strategies. Triggers of human behavior of meta-programs have been identified, among which the following are noticed: areas of privileged interest, registers of understanding, motivation triggers, attitudes towards change, action orientation, decision-making systems and metaphorical beliefs (Table no. 1).

Table no. 1. Categories of metaprograms

Content

1. Privileged areas

of interest:

- persons

- activities

- places

- informations

- things

Remarks: The manager adapts his communication to each collaborator in order to obtain their adhesion to the proposed project.

2. Registers of $\quad$ There are two registers of understanding:

understanding

- vision in detail;

- global vision.

Remarks: It is useful to know how a person's interlocutors assimilate messages and explanations of hers.
3. Triggers of
There are two orientations:
motivation
- motivation by necessity;
- stakes and possibilities offered.
There are four triggers of motivation:
- to need ("I have to ...!");
- to be necessary ("It is necessary to ...!");
- to can ("I can ...!");
- to wish ("I wish to ...!").

Remarks: Detecting the trigger of motivation for contributors is essential to obtain their understanding and adhesion.

4. Attitudes There are three types of approaches reported to those of the towards changes 
- similar (taste for similarity);

- different (desire for novelty);

- comparative (comparison trend).

Remarks: Say that change is a continuity of what is already done (the situation of similarity), announce the capacities of evolution to those who compare the advantages of the new situation with those of the old one, affirm that change is a rift in relation to the past For those who are attracted to the novelty.
5. Action
There are two orientations:
orientation
- actions driven with care to avoid troubles;
- actions generated by the will to progress, to achieve an objective.

Remarks: To know the orientation of the actions of a collaborator it is necessary to listen to his arguments to persuade us to do something.

6. Reference system There are two categories of references:

for the opinion of

- internal (decision according to its own criteria);

the group members

- external (decision by integrating the opinion of others).

Remarks: To make a decision it is necessary to know several parameters (process of choice).

7.Metaphorical There are seven types of persuasions:

beliefs

(psychological

resorts that

animate individuals,

without always

being aware)

- the fight (Life is a fight, a ratio of strengths);

- the competition (the stimulated people think it is important to overcome, to progress towards previous moments);

- the sacred (it is estimated that task is a mission);

- the game (for many individuals life is a playing field, which is why it acts randomly and prefers to risk);

- the earth (every act of everyday life is enrolled in continuity);

- the discovery (new technologies, informatics, a dedicated mission, are incentive to motivate people who are motivated by the need to discover);

- the joint work (the organization can be considered as a family, the result of a common work).

Remarks: Each individual has their own way of reporting to reality.

Source: adaptation after Esnault,P.N., Caréé, O.,Muller,J.L., 2003, p. 152-153.

NLP metaprograms are the result of subjective experience, education, professional and personal activities, systems of identification with certain heroes [Vagu, P., Stegaroiu, I., 2007, p. 413]. Unlike other aspects of NLP, in the case of meta-programs, there is no specific technique to identify them, this identification being made through questions and by developing the ability to perceive predicates, verbal and non-verbal clues offered by the interlocutor. as we understand how the person next to us thinks - which is the structure of his/her experiences - we will notice that we can perceive his / her map and we can successfully influence it. Therefore,NLP meta programs determine the quality and relationships between experiences and information at the level of our strategies, influencing how experiences are represented, sorted and 
stored.at the same time, they determine how we focus, operate information, and filter these experiences. Knowledge of the NLP metaprograms is essential, communication being facilitated by their understanding. also, because we know how an individual prefers to act, motivation is also facilitated, being able to communicate efficiently with him/her and to assist him/her in developing useful behaviors.

The mainNLP metaprograms are (figure no.2): (1) motivation direction (positive motivation, that involves focusing on what he / she wants, on the vision and dreams he / she has and negative motivation, that involves a cautious approach and focus on fears, risks, in an attempt to identify concrete solutions to minimize and limit them), (2) size filter (some individuals are used to scrutinizing actions and situations in detail, while others are satisfied only with general terms; it is good to have a balance between detail and generalization), (3) temporal reference frame (both our planning and our objectives and actions can be long, medium or short term, and it is still necessary to consider all three coordinates, concentrating on one of them at a time and setting the actions, goals and planning not only for each case, but also for the phenomenon as a whole, the nature of the stakes, people and the relationships between them, the structuring of the planning strategy, as well as the mechanisms and procedures underlying this metaprogram), (4) time orientation and relation(influences to a great extent the established goals, some people being oriented in the past, others enjoping the present, and others preparing for the future; solving a problem and challenges in an innovative way always involves creativity), (5) weight control point (individuals who relate to internal references are guided by what they want, while those who rely on external references are more connected with what they need), (6) the relationship meta-program(refers to the strategy preferred by an individual to find out the agreement (likenesses) and disagreement (differences) between different elements and entities) and (7) focus on the process (this meta-program seems to be genetically and culturally programmed to the same extent because male subjects tend to be oriented towards tasks, while female subjects are oriented towards relationship; for this reason, males look for solutions to problems, whilewomen are looking to develop relationships by talking about issues). 
Figureno. 2. List of main NLP metaprograms

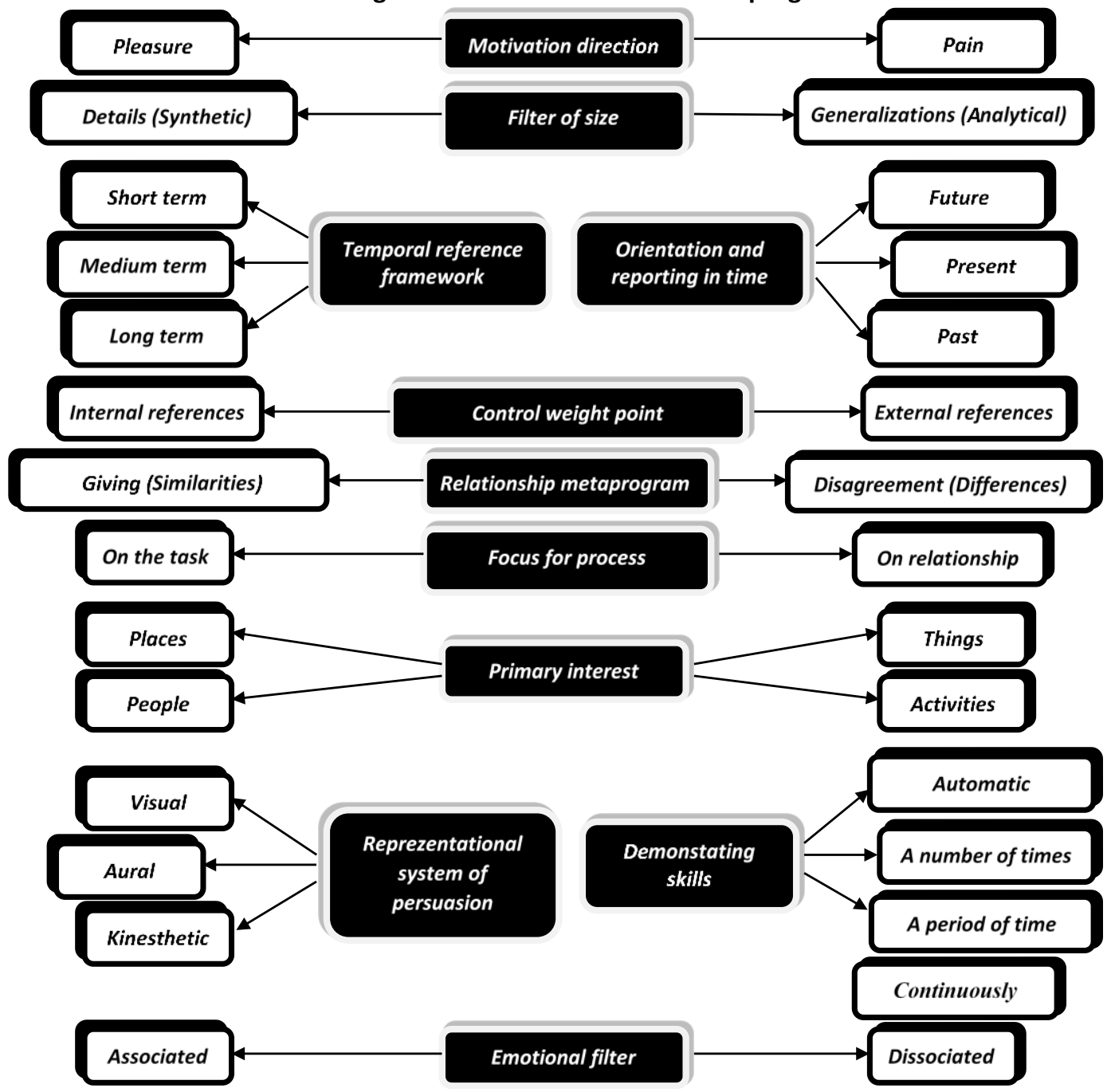

Source: author of the work.

Each individual has his/her metaprograms set in a certain way, different activities requiring different approaches and meta-programs.Ideally, teams must be formed in the organization so that all its activities are "covered" by the favourite NLP meta programs of the members of the working teams. Thus, within teams it would be created a strong sense of belonging, understanding and recognition of qualities, because they are all "good/OK", not "bad/defect", each of them being useful in a certain context, in a certain problem. 
Besides the meta programs presented above, it is worth mentioning here four more NLP meta-programs, respectively: primary interest (individuals' focus on places or people, on things or activities), belief representation system (the way in which an individual is convinced of something), demonstration of skills (refers to the strategy of a manager or leader to convince themselves of the skills of their subordinates) and the emotion filter(the strategy preferred $b y$ individuals in terms of association and dissociation of states).

\section{Reframing}

Before defining the term "reframing" it should be mentioned that the notions "frame" and "framing" refer to the perspective from which a person sees the world, perspective born from personal experiences or experiences in the environment. a person gives it a meaning according to his/her beliefs, values and things that he / she likes or does not like. In other words, it represents the meaning that a person gives to the situation itself. When a person has an unpleasant experience, what he/she does not like is his/her response to that experience. There is nothing wrong with the frames which the individual uses in different situations, except for the situation where a certain frame causes troubles. The way in which the individual changes the answer shows that the answer itself is not based on what happens in the sensory experience, but on the interpretation made by him/her. The individual has a tendency to frame beliefs, values, and things based on how he/she has perceived them in the past. In most cases, by changing the usual perception standards, he/she creates more life options. Looking at that situation from another perspective, the person can change how he or she reacts in life, can change his/her representation or perception, can change his/her state, behavior and actions. This is what reframing refers to. Reframing is the art and science of arranging words and actions in order to change the personal perspective or other person's perspective in a particular situation with the intention of initiating a change in behavior.

Reframing allows any kind of behavior to change and to identify a positive intention [Dilts, R.B., 2014, p. 124], starting from the idea that behavior is or has been an adaptive behavior depending on the situation in which it was learned and involves the transformation of problems into resources. as a particularly important aspect, it should be taken into consideration the fact that the significance entirely depends on the context of manifestation which, in turn, determines the significance of things within an organization. The way in which an individual communicates with other individual is established by using some 
unspecific verbs,such as"to communicate" or "to verify", which determine the persons concerned to use their own representation systems.

The main aim of reframing is to delimit intentional behavior [losif, C.M., 2013 , p. 55]. as a matter of fact, reframing tries to give the same situations or states new, different meanings, the purpose of the method being to transform the original meaning into a different one and to move it into a new frame with the help of which context can be noticed as well as possible. There are two forms of reframing [losif, C.M., 2013, p. 55-56]: context reframing (can be defined as the experience that generates different implications on the manifestation context) [Dilts, R.B., Lozier, J.D., 2000, p. 128] and content reframing (refers to the fact that it does not aim at changing contexts, but at changing the perspectives which a person uses, behavior flexibilization and its faster adaptation to various changes in the organization).

The ultimate goal of this method is the reframing of the thinking processes of a person with the help of various linguistic structures, because a new sense is given to a situation or state that, under other conditions, would not be effective. When a person expresses his / her opinion, it also automatically determines a behavior that transforms its meaning. With the help of linguistic markers used, that opinion is overlaid over certain models so as to give birth to a new perspective on the subject in question.

In the communication process, the positive intention associated with that person must be discovered. assuming that any behavior has a certain value and utility in a particular context, a communication process can be established with that person. By reframing the positive intention of a behavior can be obtained [losif, C.M., 2013, p. 55]. The steps of reframing are: identification and anchoring the behavior considered a problem, separating external factors from context and tracking the internal response, establishing a way of communication with the anchored party in the form of the preferred communication channel, separating the intention from the unadjusted response and identification of the positive intention that can be associated with that response, identification of the state of change so that it can be applied, accessing the new behavior and checking whether it has changed or not, checks being repeated until the old elements in that behavior are replaced with improved elements. Behavior identification is also considered a very important stage of reframing. Thus, reframingcan detach us from the objectives to be achieved, emphasizing - in particular - the correct identification of the reasons underlying the behavior. This NLP method achieves its purpose when it manages to completely change the significance of a certain information. 


\section{Discussion and Conclusions}

Particular emphasis should be placed on the employee's motivation because it has been found that hired personnel - when motivated at work - tend to achieve tasks much faster and of high quality, leading to higher performance, lower staff fluctuation and absenteeism. In most private organizations the motivation system is quite functional, but within public organizations, this system and - in particular - the remuneration system for hired personnel, is established by law, making it difficult to achieve a motivation of employees. Many steps are being taken in order to improve the motivation system and to achieve the goals of public organizations in a favorable time, but we must also expect compromises in the relationship between the employer and the employee.

\section{References}

[1] Andreas, S., Faulkner, C. (2008). NLP si succesul. Bucuresti: Ed. Curtea Veche.

[2] Bandler, R.W. (1993). Time for achange. Capitola: Meta Publications Inc.

[3] Bandler, R.W., La Valle, J. (1996). Persuasion engineering. Capitola: Meta Publications Inc.

[4] Dilts, R.B. (2014). Bazele programarii neuro-lingvistice. Bucuresti: Ed. VIDIA.

[5] Dilts, R.B. (2008). Strategiide geniu. Vol. I. Bucuresti: Ed. Excalibur.

[6] Dilts, R.B. (2007). Schimbarea sistemului de crezuri prin programare neuro-lingvistica. Bucuresti: Ed. Excalibur.

[7] Dilts, R.B. (1996). Visionary leadership skills. Capitola: Meta Publications Inc.

[8] Dilts, R.B., Lozier, J.D. (2000). Encyclopedia of systemic NLP and NLP new coding. Scotts Valley: NLP University Press.

[9] Druker, P. (1974). Management:Tasks,Responsibilities, Practices. New 「ork: Harvard University Press.

[10] Esnault,P.N., Caréé, O.,Muller,J.L. (2003). Motiver aujourd'hui, c'est posible! ESF Éditeur, CEGOS.

[11] Hall, L.M. (2007). Spiritul programarii neuro-lingvistice. Bucuresti: Ed. Curtea Veche.

[12] Haskins,H.S. (1947). TreasureChest: Glory", New YorkTimes.

[13] losif, C.M. (2013). Utilizarea performanta a programarii neurolingvistice in managementul firmei. Bucuresti: Ed. C.H.Beck.

[14] losif, C.M., Socaciu, T. (2009). Modelling vs. training in organizations in The $33^{\text {rd Annual }}$ Congress of the American Romanian Academy of Arts and Science (ARA), Vol. I. Sibiu: Univ. Alma Mater.

[15] Knight, S. (2004). Tehnicile programării neuro-lingvistice. Bucuresti: Ed. Curtea Veche.

[16] Lewis, B., Pucelick, F. (1990). Magicnlpdemistified.Portland: Metamorphous Press.

[17] Molden, D. (2007). Business masterclass: driving peak performance with NLP. London: FT Press. 


\section{HOLISTICA Vol 10, Issue 1, 2019}

[18] O'Connor, J. (2012). Manual de programare neuro-lingvistica. Ghid practic pentru obtinerea rezultatelor pe care le doresti. Bucuresti: Ed. Curtea Veche.

[19] O'Connor, J. (2001). The NLP workbook. London: Harpers Collins Publishers.

[20] Vagu, P., Stegaroiu, I. (2007). Motivarea in munca. De la teorie la practica. Targoviste: Ed. Bibliotheca.

[21] Vagu, P., Stegaroiu, I. (2006). Lideriatul. De la teorie la practica. Targoviste: Ed. Bibliotheca.

[22] Zait, D., Spalanzani,A. (2006). Cercetareaineconomie simanagement. Repereepistemologice simetodologice.Bucuresti: Ed. Economica. 